\title{
Performance Analysis of a Single Underground Thermal Storage Borehole Using Phase Change Material
}

\author{
A. M. Bayomy Hiep V. Nguyen Jun Wang Seth B. Dworkin
}

\begin{abstract}
Ground source heat pumps (GSHP) are used to provide both heating and cooling to a given system. These heat pumps transfer heat efficiently between the system and the ground. Despite this high efficiency, there has been a low adoption rate for GSHPs owing to limited usage in commercial structures and buildings primarily due to high installation costs, but also due to a lack of drilling space and unbalanced heating/cooling loads. Phase change materials (PCMs) can absorb, store and release large amounts of latent heat over a defined narrow temperature range while the material changes phase or state. The main goal of this paper is to be able to predict numerically the performance of a single borehole with the effect of implementing PCMs. In order to successfully proceed with the discussion, two main objectives for this paper are presented. The first objective is to establish a finite element model of a single borehole with accurate assumptions in order to achieve an accurate prediction over four years of operation for a GSHP. Then, the second objective of the paper is to investigate the effect of using PCM in the borehole of GSHP to help maintain a more stable ground temperature range. Two scenarios of different PCM volumes and melting temperatures are presented. It was found that the performance enhancement due to PCMs reaches up to $35 \%$ in monthly average COP. In addition, PCMs show great potential to smooth the ground thermal response.
\end{abstract}

\section{INTRODUCTION}

The utilization of efficient space heating and cooling systems has become rather urgent owing to the fact that $40 \%$ of the total energy consumption worldwide is attributed to space heating and cooling (De Ridder et al., 2011). Space heating and cooling has a high energy demand and has a significant impact on energy consumption. Thus, it has been necessary to find efficient alternatives to pre-existing methods for space heating and cooling in order to reduce energy consumption and greenhouse emission of such devices.

One possible solution to the problem of high energy consumption of space heating and cooling systems is through the adoption of ground source heat pumps (GSHPs). GSHPs utilize the ground as an infinite heat sink and heat source for both cooling and heating (Florides and Kalogirou, 2007). The efficiency of the heat pump lies in the fact that ground temperature at a particular depth remains nearly constant over the year. However, despite the prospective benefits of GSHPs, there are several limitations with the use of such systems. GSHPs 
IGSHPA Research Track

Stockholm September 18-20, 2018

are rather challenging to utilize due to possible lack of drilling space, imbalance in heating or cooling, and high installation costs of the system.

One of the main problems in utilizing the cooling process of GSHPs is that long-term heat addition to the ground may cause increases in ground temperature resulting in a detriment th the cooling efficiency of the GSHP for a single borehole (Hu et al., 2010). According to a study by Zheng (2013), it was found that changes in ground temperature were most noticeable in the region within $0.5 \mathrm{~m}$ of the borehole. These temperature changes were most noticeable during the first few years of operation, wherein changes in the temperature of the ground can lead to inefficient GSHP functioning due to insufficient temperature gradient (Zheng,, 2013), as well as ecological problems in the soil (Wu et al., 2014). However, it is possible to address this issue by ensuring that boreholes of GSHPs are separated by $6 \mathrm{~m}$ (ASHRAE, 2011). It is highly important that borehole field arrangements (i.e. the borehole array size) are taken into consideration as these arrangements can have a significant effect on the ground temperature and the overall performance of GSHPs.

Several models and studies have been done in order to properly determine the most feasible design for GSHPs. These models predict the performance of a single borehole, and in the process provide a model of how ground temperature changes with the operation of a GSHP. In the model by De Paepe and Willems (2001), they considered a three-dimensional numerical model wherein pure conduction was considered in the interaction between soil and other materials. In the model by Zhang et al., they considered a numerical model of heat transfer wherein the distance between boreholes and backfill material thermal conductivity were considered as the parameters in geothermal heat exchange (Zhang et al., 2015). Finally, in the numerical model designed by Law and Dworkin, it was found that the recommended distance of $6 \mathrm{~m}$ in between boreholes, as recommended by ASHRAE, does not always provide an effective means of avoiding thermal interactions between the boreholes of GSHPs (Law and Dworkin, 2016). Kuzmic, et al. (2016) conducted a 2-D model to study the heat transfer of hybrid system of GSHP and conventional HVAC. They noticed that the hybridization has a potential effect on ground temperature stability.

To the best of the authors' knowledge, the existing research on predicting the performance and efficiency of GSHPs is scarce and severely incomplete owing to the oversimplifications numerical models take into consideration. One such assumption leading to oversimplification is the consideration that only pure conduction occurs between the soil and boreholes, which then neglects the effect of convection. Furthermore, other models neglect the porous behaviour of soil, which can then affect the heat transfer models. In addition, models similarly neglect turbulent heat transfer inside the heat exchange system and, in the process, the models consider constant heat flux. These neglected factors can be taken into consideration by establishing a finite elements model of a single real borehole. This proposed model takes into consideration the turbulent heat transfer of the circulating fluid, along with load variation over time, as well as the actual heat flux profile inside the soil, and actual heat pump performance

A proposed technique in which the GSHPs may provide better efficiency is through the conversion of the geothermal heat exchanger from infinite volume to a finite volume of thermal storage material (TSM). This finite volume of TSM can then address problems in thermal interaction between boreholes, ground temperature changes, and land utilization. Land utilization can be further addressed through the implementation of phase change material (PCM) in the borehole.

PCMs are commonly used in thermal storage media, and have been long-recognized as both sustainable and environmentally-friendly (Baetens et al, 2010; Lin et al., 2014). PCMs are able to absorb, store and release large amounts of latent heat over a given defined narrow temperature range. It has been shown that PCM heat exchangers are able to achieve high thermal performance (Medrano et al., 2009; Rabin and Korin, 1996). PCMs 
have been used in heat exchangers such as in double pipe copper tubes (Longeon et al., 2013), flat plate (Liu et al., 2014), and shell and tube heat exchangers (Hosseini et al., 2014; Trp et al., 2006).

The application of PCMs to GSHP systems can lead to the enhancement of the overall performance of the heating and cooling system through smoothening the abrupt heating and cooling waves generated from variations in building load of GSHPs. The ability of PCM to aid in increasing the efficiency of GSHPs can be attributed to the results by $\mathrm{Wu}$ and $\mathrm{Li}$ wherein PCMs were shown to have significantly better performance as compared to other backfilling materials used in geothermal heat exchange systems (Wu, 2008; Li, 2014). Similar results have been shown in studies by Lei and Zhu (2009), and Yang et al. (2014).

In this study, paraffin was utilized as PCM in ground heat exchange systems, wherein their effects on GSHPs were simulated over the span of four years. Paraffin was chosen as the PCM due to its high latent heat of 190 $\mathrm{kJ} / \mathrm{kg}$. With this latent heat over a defined narrow temperature range, the TSM layer can absorb and release large amounts of heat without causing significant ground temperature variation.

In the present study, two scenarios of implementing the PCMs (Paraffin) in the ground heat exchanger are simulated for four years of operation. The heat pump COP is evaluated over four years of operation for a balanced building. Section 2 presents the methodology, followed by the results and discussion in section 3 . Finally, Section 4 highlights the findings obtained and the conclusions.

\section{METHODOLOGY}

The finite elements study consists of two main parts as follow:

1- Establishing a finite element model using COMSOl Multiphysics for a single borehole.

2- Investigating the effect of two different scenarios of the PCM's melting temperature and volume.

\section{Building load}

It is important to note that one of the assumptions made in creating the model in this study is that a balanced building load is considered, where in 8760 hours in a year, half is considered to utilize heating and the other half utilized cooling. Figure 1(a) illustrates hourly building load variation. The finite element model of this study simulates a single borehole. The building loads have been normalized to $3.5 \mathrm{~kW}$ ( 1 ton) maxima for both cooling and heating processes. This normalization is illustrated in Figure 1(b). Finally, taking into consideration this assumption, the borehole depth was estimated to be about 60-80 meters per ton heating and cooling.

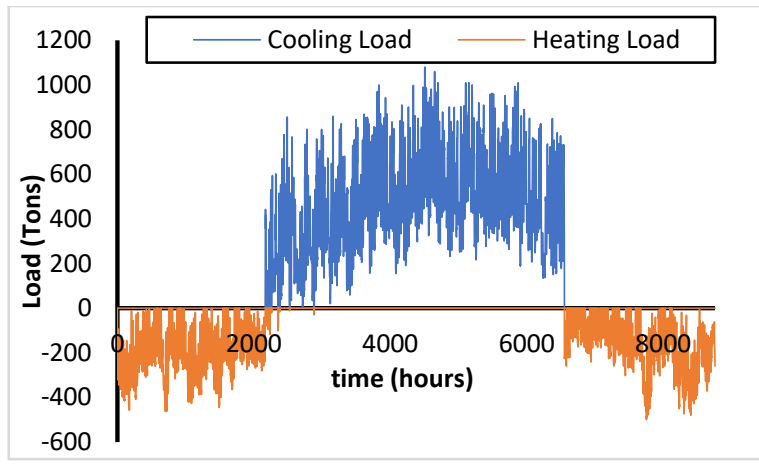

(a) Raw heating and cooling load values

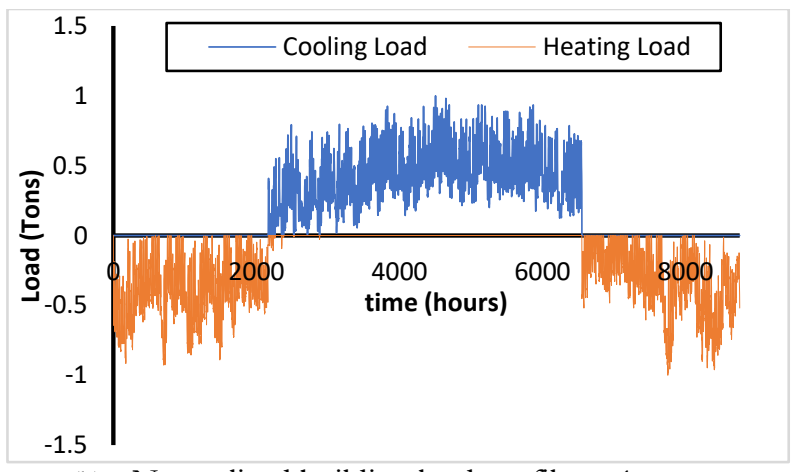

(b) Normalized building load profile to 1 ton

Figure 1 Building load variation for a balanced building 
IGSHPA Research Track

Stockholm September 18-20, 2018

\section{Heat pump performance}

The heat pump used in the study is the 5T ClimateMaster Tranquility Water-to-Water Series Model TMW060. The heat pump was tested by the industrial partner, McClymont and Rak Engineers, Inc. The actual performance of the heat pump was evaluated to be $25 \%$ below the manufacturer specification for both heating and cooling. The actual performance of the heat pump was tested under load/source flow rate of $56.78 \mathrm{~L} / \mathrm{min}$ (15 gpm) and load side EWT (Entering Water Temperature) of $38^{\circ} \mathrm{C}$ for cooling and $15{ }^{\circ} \mathrm{C}$ for heating. Figure 2 shows the manufacturer and actual heat pump performance for heating and cooling.

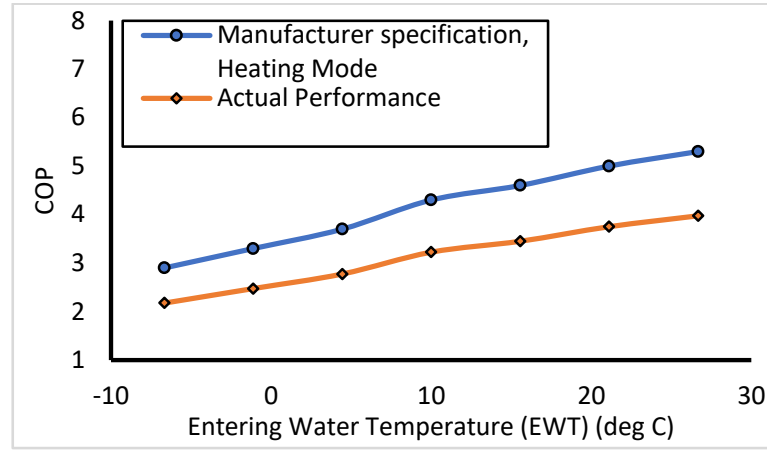

(a) Heat Pump performance for heating mode

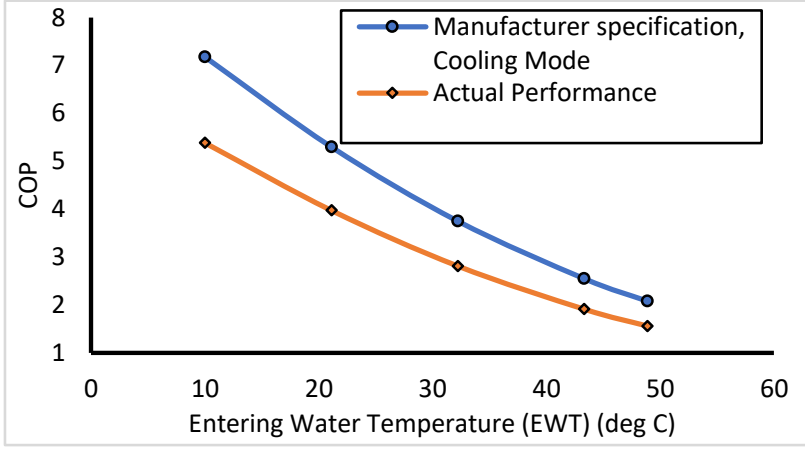

(b) Heat Pump performance for cooling mode

Figure 2 Actual and manufacturer specification for heat pump performance

\section{Finite elements model description}

In this study, the three-dimensional numerical model was created by using the finite elements techniques (COMSOL Multiphysics) for a single borehole of a GSHP, which is buried at a depth of $60 \mathrm{~m}$. In addition, a U-loop heat exchanger (HEX) was placed at the center of the borehole, wherein this U-loop was characterized with outer and inner diameters given to be $42.2 \mathrm{~mm}$ and $34.0 \mathrm{~mm}$, respectively. The separation distance of the U-loop HEX used in this study was $0.065 \mathrm{~m}$. Figure 3(a) shows the two main layers which have been used to simulate material surrounding the U-loop. The layers consist of $0.1524 \mathrm{~m}$ of grout material layer, and $4 \mathrm{~m}$ of soil layer. Table 1 gives a summary of the thermal properties of each of the layers. It should be noted as well that a tetrahedral element was utilized in describing the numerical model, and an analysis of grid independence was conducted.

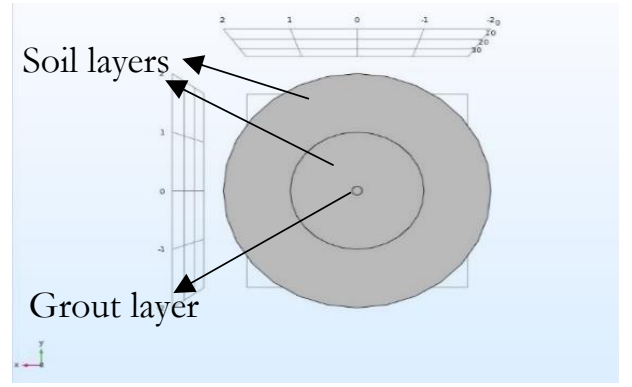

(a)

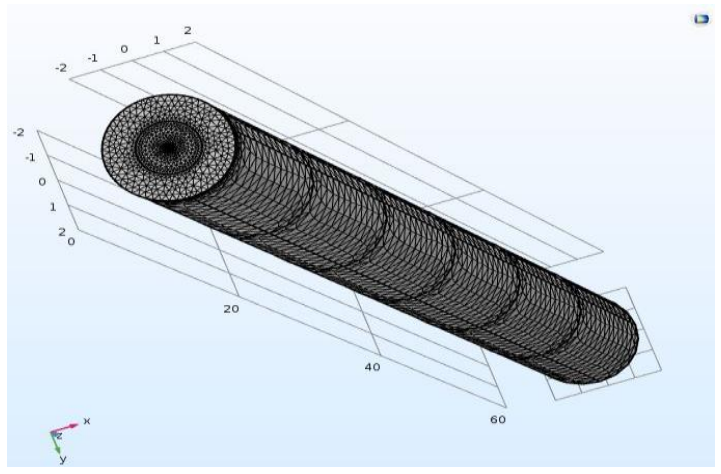

(b)

Figure 3 Model geometry and meshing 
IGSHPA Research Track

Stockholm September 18-20, 2018

Table 1. Layer properties

\begin{tabular}{cccc}
\hline \multirow{2}{*}{ Material } & Density $\left(\mathbf{k g} / \mathrm{m}^{3}\right)$ & $\begin{array}{c}\text { Thermal Conductivity } \\
(\mathbf{W} / \mathbf{m} . \mathbf{K})\end{array}$ & Specific heat $(\mathrm{J} / \mathbf{k g} . \mathbf{K})$ \\
\hline \hline Soil & 1900 & 2 & 1053 \\
Grout & 1700 & 0.7 & 1647 \\
\hline
\end{tabular}

An assumption utilized with the present numerical model is that the ground water movement inside the soil is negligible, along with the assumption that both the grout material and soil are homogeneous with constant properties. From these assumptions, a system of governing equations to describe heat transfer inside both layers and in the U-loop HEX is obtained. The equations are given as:

$\left(\rho_{\mathrm{s}} \mathrm{c}_{\mathrm{s}}\right) \cdot \frac{\partial \mathrm{T}}{\partial \mathrm{t}}+\left(\rho_{\mathrm{s}} \mathrm{c}_{\mathrm{s}}\right) \mathrm{U} \cdot \nabla \mathrm{T}=\nabla \cdot\left(\mathrm{k}_{\mathrm{s}} \cdot \nabla \mathrm{T}\right)$

$\left(\rho_{\mathrm{l}} A \mathrm{c}_{\mathrm{p}_{\mathrm{l}}}\right) \cdot \frac{\partial \mathrm{T}}{\partial \mathrm{t}}+\left(\rho \cdot \mathrm{A} \cdot \mathrm{c}_{\mathrm{p}_{\mathrm{l}}}\right) \mathrm{U} \cdot \nabla \mathrm{T}=\nabla \cdot\left(\mathrm{A} \cdot \mathrm{k}_{\mathrm{l}} \cdot \nabla \mathrm{T}\right)+\frac{1}{2} \mathrm{f} \cdot \frac{\rho \mathrm{A}}{\mathrm{d}}|\mathrm{u}| \mathrm{u}^{2}$

The turbulent Nusselt number inside the U loop HEX is obtained as follow:

$\mathrm{Nu}_{\mathrm{D}}=0.027 \operatorname{Re}_{\mathrm{D}}^{4 / 5} \cdot \operatorname{Pr}^{\mathrm{n}}$

In the above equations $\rho_{\mathrm{s}}$ is density of solid layers (e.g. soil or grout), $\mathrm{c}_{\mathrm{p}_{s}}$ is specific heat of solid, $\mathrm{U}$ is the velocity field vector, $T$ is the temperature, $K s$ is thermal conductivity of solid, $\rho_{l}$ is liquid's density, $c_{p_{1}}$ is liquid's specific heat, $\mathrm{k}_{\mathrm{l}}$ is liquid's thermal conductivity, $\mathrm{f}$ is the friction factor of the $\mathrm{U}$ loop HEX tube, $\mathrm{A}$ is the cross section area of the $\mathrm{U}$ loop HEX tube, $\mathrm{Nu}_{\mathrm{D}}$ is Nusselt number, $\mathrm{Re}_{\mathrm{D}}$ is Reynolds number, Pr is Prandtl Number, and $\mathrm{n}$ is a constant given to be 0.4 for cooling and 0.3 for heating.

The procedure for formulating the finite element model is outlined in Figure 4. For every time step, the model obtains the value of the load and the outlet water temperature predicted from the borehole. These two parameters aid in evaluating the COP of the heat pump, and from here the amount of heat added or extracted by the heat pump is then calculated. Knowledge of this value aids in calculating the inlet water temperature of the borehole in the proceeding time step.

The convergence criterion at each iteration is set as follows: at every iteration, the average relative error of $\mathrm{U}$ and $\mathrm{T}$ are computed. These are obtained via the following relation:

$$
\mathrm{R}=\frac{1}{\mathrm{n} \cdot \mathrm{m}} \sum_{\mathrm{i}=1}^{\mathrm{i}=\mathrm{m}} \sum_{\mathrm{j}=1}^{\mathrm{j}=\mathrm{n}}\left|\frac{\left(\mathrm{F}_{\mathrm{i}, \mathrm{j}}^{\mathrm{s}+1}-\mathrm{F}_{\mathrm{i}, \mathrm{j}}^{\mathrm{s}}\right)}{\mathrm{F}_{\mathrm{i}, \mathrm{j}}^{\mathrm{i}}}\right|
$$

where $F$ represents one of the independent parameters, s represents the number of iterations, and (i, j) represent the $\mathrm{x}$ and $\mathrm{y}$ coordinates. The solution reached convergence when $\mathrm{R}$ was below $1 \times 10-6$ for each independent parameter.

The implementation of PCMs in the borehole is established through the use of two models. Both of these models utilize paraffin-filled pipes which are inserted around the U-loop HEX tube. Practically, PCM filled tubes will be inserted and arranged in the vicinity of the borehole HEX. The dimeter of each PCM tube was 34 $\mathrm{mm}$. PCMs possess a transition temperature, the transition temperature of paraffin wax is about $4^{\circ} \mathrm{C}$. The first model, herein referred to as Model (A), consists of 12 PCM filled pipes with thin PCM rectangular layers placed between the U-loop HEX legs. 
IGSHPA Research Track

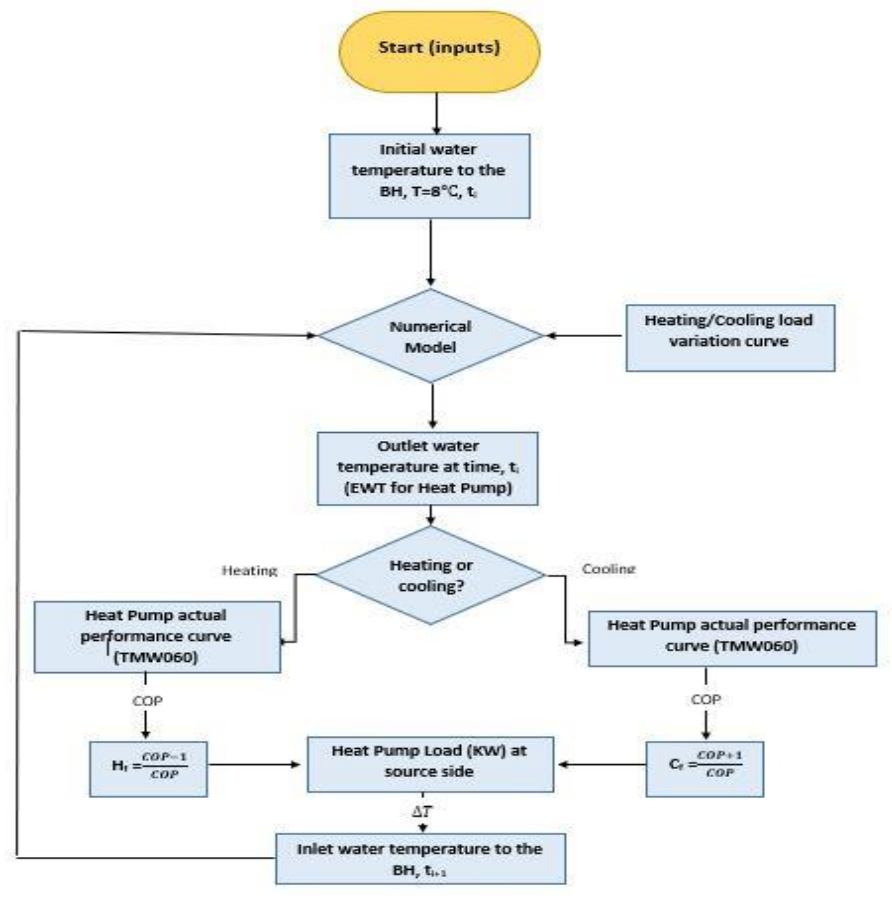

Figure 4 Algorithm procedure

The PCM has a melting temperature of $12^{\circ} \mathrm{C}$. Conversely, the second model (Model (B)) is similar to model (A) but in addition has another $12 \mathrm{PCMs}$ composed of filled pipes with a melting temperature of $2^{\circ} \mathrm{C}$. Both of these models are illustrated in Figure 5, and the properties of the PCMs are summarized in Table 2. Paraffin wax is an organic PCM, so it is environmentally safe, reliable, less expensive, non-corrosive, more stable below $500{ }^{\circ} \mathrm{C}$, long-term freeze-melt cycles.

Other factors taken into consideration are the boundary conditions implemented in the model. Included in these boundary conditions are the fluid flow rate inside the U-loop, which is given to be $11.5 \mathrm{~L} / \mathrm{m}$ ( $3 \mathrm{gpm})$. In addition, the outer and bottom portion of the soil layer surface is treated as by obtaining outward heat flux by considering the far field distance to be $30 \mathrm{~m}$ from the center of the borehole. Finally, the top portion of the borehole is treated to be an open boundary to the external environment, the temperature of which varies according to the session.

\section{RESULTS AND DISCUSSION}

In evaluating the results obtained from the model, it should be noted that the starting month of each year was set to be April. This means that each year begins with cooling demand followed by heating demand. It was found that the minimum COP for cooling is 2.3, while for heating it is 2.6 at the end of each session, where the ground temperature was found to either be colder after heating, or hotter after cooling. The same trend was observed for monthly average COP. Results are summarized in Figures 6 and 7. The temperature contours of the borehole at $30 \mathrm{~m}$ depth right after cooling and heating sessions in the fourth year of operation are visualized in Figure 8. 
IGSHPA Research Track

Stockholm September 18-20, 2018

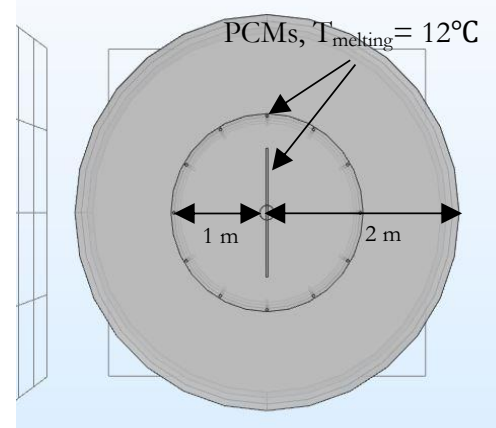

(a) $\operatorname{Model}(\mathrm{A})$

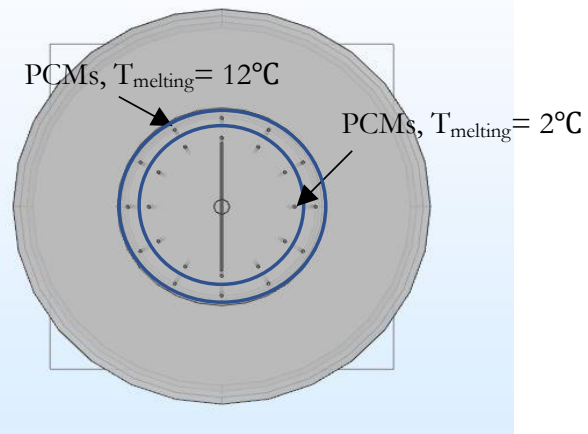

(b) Model (B)

Figure 5 Models with PCMs pipes

Table 1. PCMs properties

\begin{tabular}{cc}
\hline Paraffin & Properties \\
\hline \hline Density $\left(\mathrm{kg} / \mathrm{m}^{3}\right)$ & 760 for liquid, 850 for solid \\
Thermal conductivity $(\mathrm{W} / \mathrm{m} . \mathrm{K})$ & 0.1 \\
Heat capacity $(\mathrm{J} / \mathrm{kg} \cdot \mathrm{K})$ & 2140 \\
Latent heat $(\mathrm{kJ} / \mathrm{kg})$ & 190 \\
Melting temperature $\left({ }^{\circ} \mathrm{C}\right)$ & $0^{\circ} \mathrm{C}-35^{\circ} \mathrm{C}$ \\
\hline
\end{tabular}

In predicting the effect of the implementation of PCMs in the borehole, it was found that PCMs indeed provide smoothing to the ground thermal response. This smoothing is manifested by the behavior of COP variation with time. It was also found that the enhancement of the COP of model (A) in the daily average COP reaches up to $50 \%$, while the monthly average COP was increased up to $35 \%$. Moreover, the average enhancement percentage of model (A) over four years of operation was found to be 10 to $12 \%$. Figure 9 shows the results outlined for model (A).

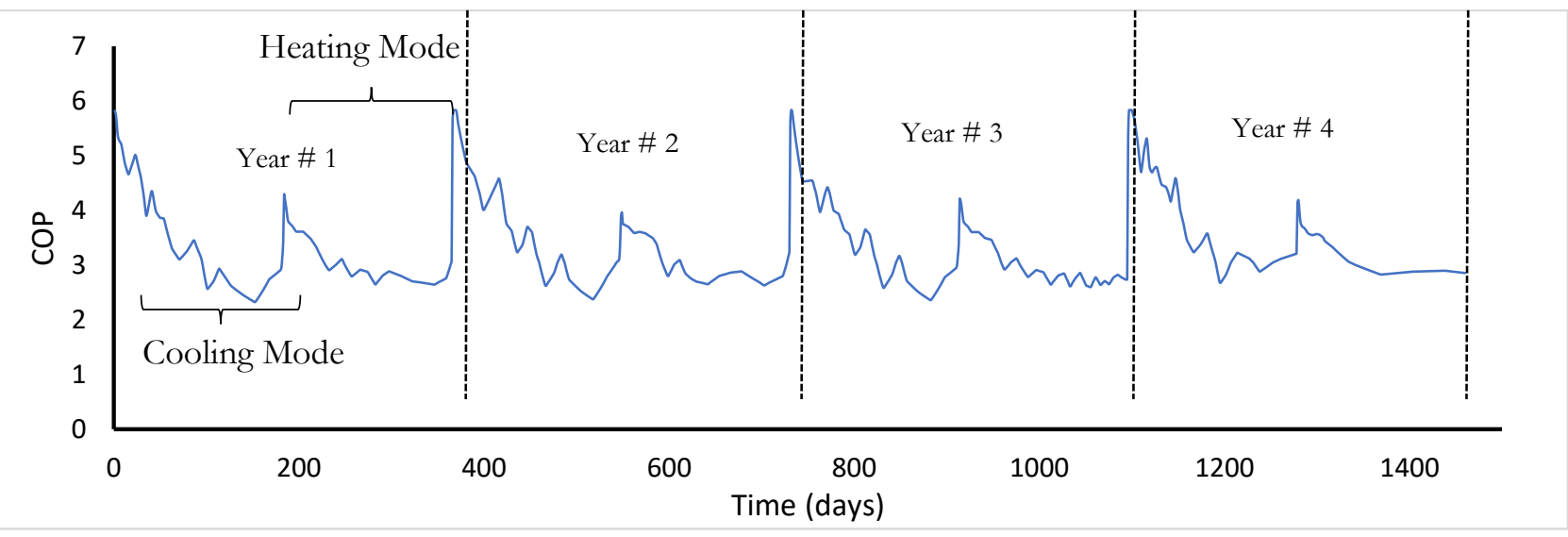

Figure 6 Daily average COP for $60 \mathrm{~m}$ borehole without PCMs 


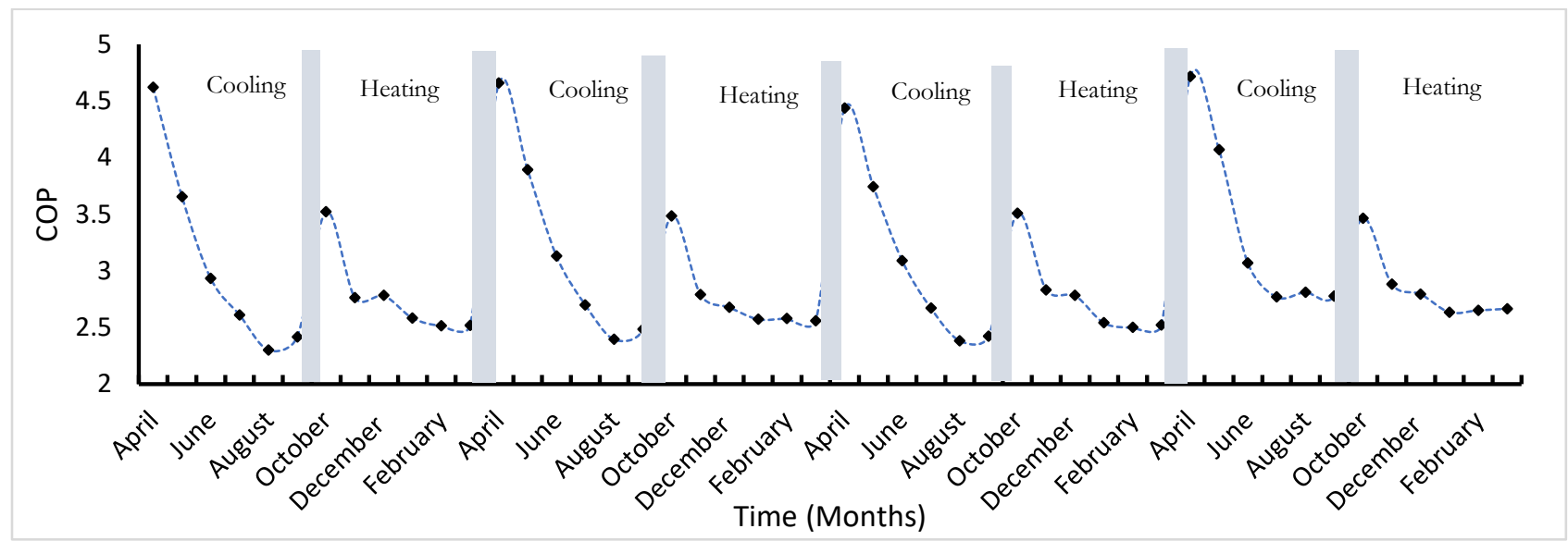

Figure 7 Monthly average COP for $60 \mathrm{~m}$ borehole without PCMs

Figure 10 shows the daily average COP of model (B) compared to a $60 \mathrm{~m}$ borehole without PCMs. It was noted that the enhancement percentages reach up to $25 \%$ and $22 \%$ for daily and monthly average COP, respectively. Although the total volume of PCMs was larger in model (B) compared to model (A), the enhancement percentage achieved by model (A) was greater than that for model (B). This means that the PCM's volume is not the only factor that governs performance. PCM melting temperature as well as the location of the PCM with respect to the U-loop ground heat exchanger are also factors that effect on the performance of the system.

\section{CONCLUSION}

In this study, a finite element model was established in order to simulate a single borehole for a balanced building. The coefficient of performance of the GSHP was evaluated over four years of operation. Furthermore, the effect of using PCMs was investigated and it was found that the implementation of such material enhances the overall performance of the system by smoothing the sudden heating and cooling waves of the ground, which can be attributed to load variation. A possible extension of this model would be a way to optimize the volume, location, and melting point of PCMs, which could then aid in achieving the highest enhancement percentage as compared to existing GSHP boreholes without PCMs.

$\stackrel{x}{L}$

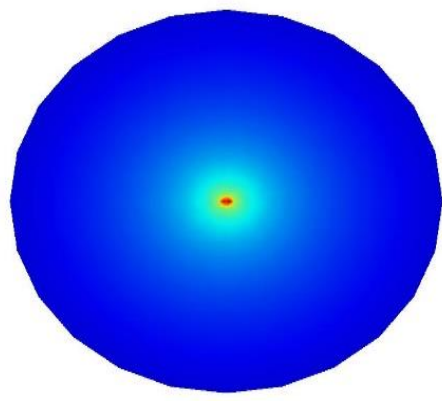

(a) Temperature contours at the end of cooling session

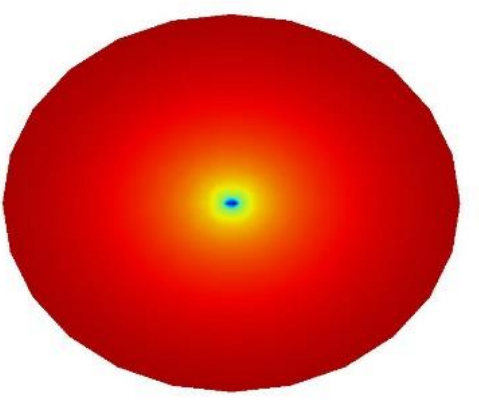

(b) Temperature contours at the end of heating session

Figure 8 Temperature contours at $30 \mathrm{~m}$ depth on fourth year 
IGSHPA Research Track

Stockholm September 18-20, 2018

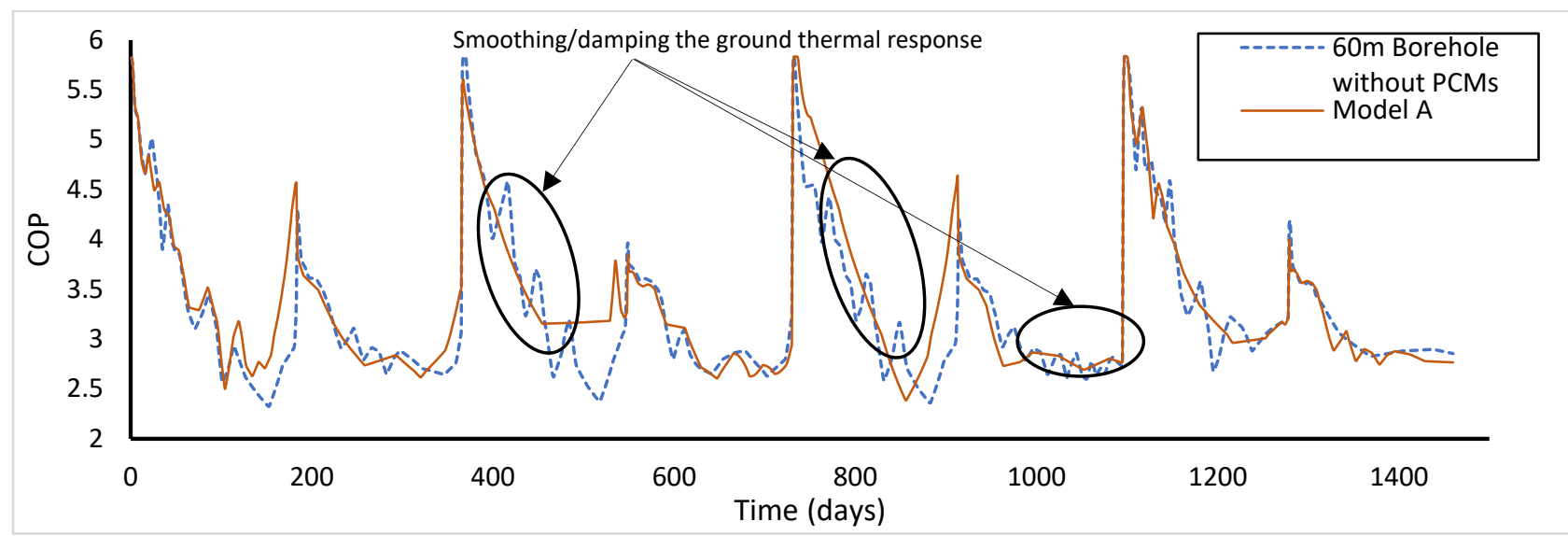

Figure 9 Daily average COP of model (A) and 60m depth borehole without PCMs

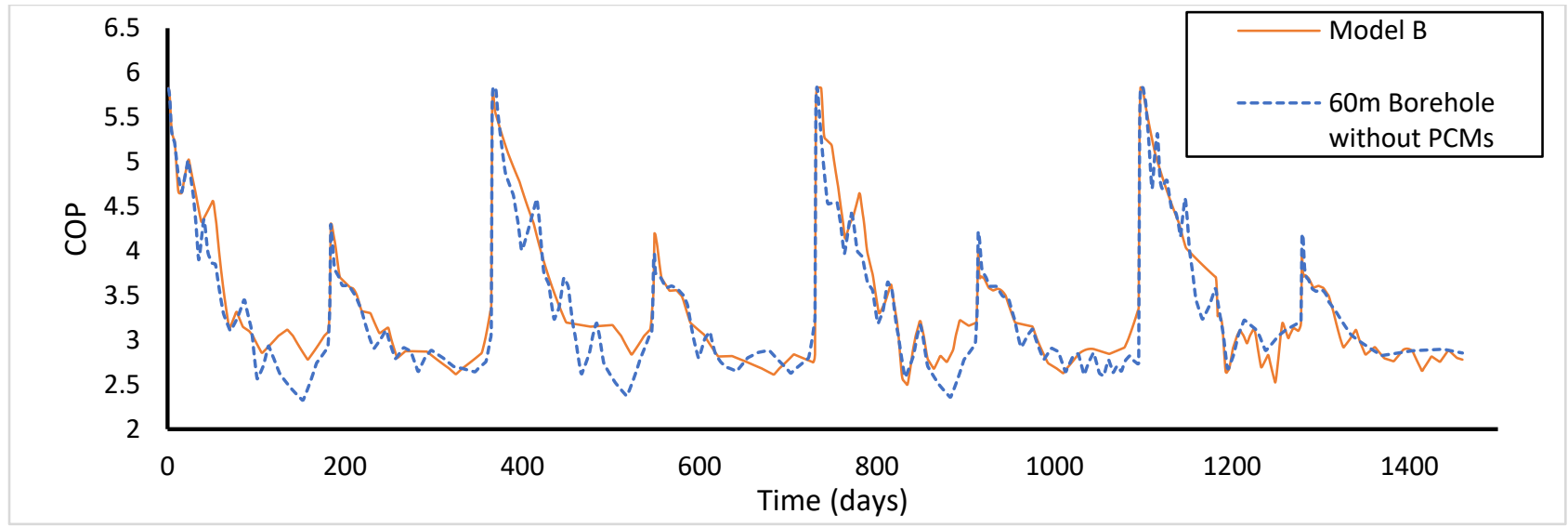

Figure 10 Daily average VOP of Model(b) and 60m depth borehole without PCMs

\section{ACKNOWLEDGEMENTS}

This research was undertaken, in part, thanks to funding from the Canada Research Chairs program. We would also like to acknowledge the Natural Sciences and Engineering Research Council of Canada, Ontario Centres of Excellence, and McClymont and Rak Engineers Inc. for financial support. Furthermore, we would like to thank Ladislav Rak of McClymont and Rak for data and helpful discussion.

\section{REFERENCES}

De Ridder, F., M. Diehl, G. Mulder, J. Desmedt, and J. Van Bael. 2011. An optimal control algorithm for borehole thermal energy storage systems. Energy \& Buildings, 43(10), 2918-2925. 10.1016/j.enbuild.2011.07.015

Florides, G., and S. Kalogirou. 2007. Ground heat exchangers-A review of systems, models and applications. Renewable Energy, 32(15), 2461-2478. 10.1016/j.renene.2006.12.014

Hu, S., W. Song, Y. Zhang, D. Pan, T. Meng. 2010. Study of Cold/Hot Stacking Problem Based on Balance Storage of Ground Source Heat Pump. 2nd International Conference on Computer Engineering and Technology. Chengdu, China. April 16-18.

Li, S., W. Yang, and X. Zhang. 2009. Soil temperature distribution around a U-tube heat exchanger in a multifunction ground source heat pump system. Applied Thermal Engineering 29 (17): 3679-86. 
IGSHPA Research Track

Stockholm September 18-20, 2018

Zheng, X. 2013. Long-term effects of ground source heat pumps on underground temperature. In: Proceedings of the COMSOL Conference.

Wu C., C. Hui, W. Wang, X. Li, and W. Fu. 2014. Characteristics of ground temperature and system performance for the intermittent operation of GSHP system. Environ, Energy And Sust Dev 2014:123-7.

Rybach, L., and W. Eugster. 2010. Sustainability aspects of geothermal heat pump operation, with experience from switzerland. Geothermics 39 (4): 365-9.

ASHRAE. 2011 ASHRAE Handbook-HVAC Systems and Equipment. SI ed. Atlanta: ASHRAE; 2011.

Tzaferis, A., D. Liparakis, M. Santamouris, and A. Argiriou. 1992. Analysis of the accuracy and sensitivity of eight models to predict the performance of earth-to-air heat exchangers. Energy \& Buildings 18 (1): 35-43.

Bi, Y., L. Chen, and C. Wu. 2002. Ground heat exchanger temperature distribution analysis and experimental verification. Applied Thermal Engineering 22 (2): 183-9.

Mihalakakou, G., M. Santamouris, and D. Asimakopoulos. 1994. Modelling the thermal performance of earth-toair heat exchangers. Solar Energy 53 (3): 301-5.

Bojic, M., N. Trifunovic, G. Papadakis, and S. Kyritsis. 1997. Numerical simulation, technical and economic evaluation of air-to-earth heat exchanger coupled to a building. Energy 22 (12): 1151-8.

De Paepe M, N. Willems. 2001. 3D unstructured modelling technique for ground-coupled air heat exchanger. In: Clima 2000/Napoli World Congress, Napoli, Italy. p. 15-8.

Zhang, W., H. Yang, L. Lu, and Z. Fang. 2015. Investigation on influential factors of engineering design of geothermal heat exchangers. Applied Thermal Engineering $84: 310-9$.

Law, Y. and S. Dworkin. 2016. Characterization of the effects of borehole configuration and interference with long term ground temperature modelling of ground source heat pumps.

Kuzmic, N., Y. Law, and S. Dworkin. 2016. Numerical heat transfer comparison study of hybrid and non-hybrid ground source heat pump systems. Applied Energy 165 : 919-29.

Longeon, M., A. Soupart, J. Fourmigue, A. Bruch, and P. Marty. 2013. Experimental and numerical study of annular PCM storage in the presence of natural convection. Applied Energy 112 (10): 175-1504.

Liu, Ming, M. Belusko, N. Steven Tay, and F. Bruno. 2014. Impact of the heat transfer fluid in a flat plate phase change thermal storage unit for concentrated solar tower plants. Solar Energy 101 : 220-31.

Hosseini, M., M. Rahimi, and R. Bahrampoury. 2014. Experimental and computational evolution of a shell and tube heat exchanger as a PCM thermal storage system. International Communications in Heat and Mass Transfer $50: 128-36$.

Trp, A., K. Lenic, and B. Frankovic. 2006. Analysis of the influence of operating conditions and geometric parameters on heat transfer in water-paraffin shell-and-tube latent thermal energy storage unit. Applied Thermal Engineering 26 (16): 1830-9.

Baetens, R., B. Jelle, and A. Gustavsen. 2010. Phase change materials for building applications: A state-of-the-art review. Energy \& Buildings 42 (9): 1361-8.

Lin, W., Z. Ma, M. Sohel, and P. Cooper. 2014. Development and evaluation of a ceiling ventilation system enhanced by solar photovoltaic thermal collectors and phase change materials. Energy Conversion and Management $88: 218-30$. 
Medrano, M., M. Yilmaz, M. Nogués, I. Martorell, J. Roca, and L. Cabeza. 2009. Experimental evaluation of commercial heat exchangers for use as PCM thermal storage systems. Applied Energy 86 (10): 2047-55.

Rabin, Y., E. Korin. 1996. Incorporation of phase change materials into a ground thermal energy storage system: theoretical study. J. Energy Res. Technol. 118. pp. 237-241.

Wu, C. 2008. Feasibility Analysis of the Ground Source Heat Pump Backfilled With Phase Change Materials. Tianjin University, Tianjin.

Li, Q. 2014. Study on Heat Transfer Characteristics of Phase Change Material Backfilling Ground Source Heat Pump. Donghua University, Shanghai.

Bottarelli, M., M. Bortoloni, and Y. Su. 2015. Heat transfer analysis of underground thermal energy storage in shallow trenches filled with encapsulated phase change materials. Applied Thermal Engineering 90 : 1044-51.

Lei, H. and N. Zhu. 2009. Analysis of phase change materials (PCMs) used for borehole fill materials. Geothermal Resources Council Annual Meeting 2009. Reno, USA. vol. 33. pp. 83-88.

Yang, W., L. Sun and X. Wu. 2014. Energy storage and heat transfer characteristics of ground heat exchanger with phase change backfill materials. Trans. Chinese Soc. Agric. Eng. (Trans. CSAE). vol. 30 (24). pp. 193-199.

COMSOL Multiphysics, retrieved from http://www.comsol.com/comsol-multiphysics, March, 2015. 